\title{
Growth efficiency-survivorship relationship and effects of spacing on relative diameter growth rate of Japanese cedars
}

\author{
Biing T. Guan ${ }^{\mathrm{a}, *}$, Shu-Tzong Lin ${ }^{\mathrm{b}}$, Ya-Hui Lin ${ }^{\mathrm{a}}$, Yi-Sui $\mathrm{Wu}^{\mathrm{c}}$ \\ ${ }^{a}$ School of Forestry and Resource Conservation, National Taiwan University, No. 1, Section 4, Roosevelt Road, Taipei 10617, Taiwan \\ ${ }^{\mathrm{b}}$ Department of Natural Resources, National Ilan University, Yilan city City 26042, Taiwan \\ ${ }^{\mathrm{c}}$ Experimental Forest, National Taiwan University, Chu-Shan 55743, Taiwan
}

Received 5 June 2007; received in revised form 19 November 2007; accepted 27 November 2007

\begin{abstract}
Relative growth rate (RGR) is considered to be one of the most sensitive measures of competitive ability. As such, RGR should correlate positively with survivorship. The proposition, however, has not been fully tested with long-term data. Another question that has not been fully addressed is the long-term effect of initial density on the RGRs of survivors. Based on data from a long-term Japanese cedar (Cryptomeria japonica) spacing trial (with square spacing of 2, 3, 4, and $5 \mathrm{~m}$ ), we tested the following two hypotheses: (1) within each spacing, survivors have

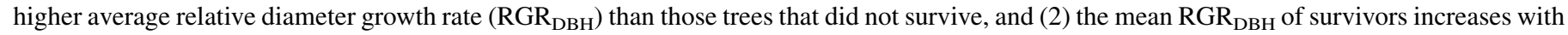
increasing initial spacing. A two-parameter monomolecular model and nonlinear mixed-effects regression were used to model individual tree

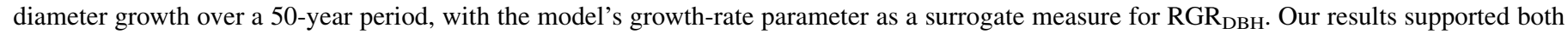
hypotheses conditionally. Survivors were indeed the more efficient ones, but only when competition became intense. Our study suggested that selfthinning likely thins out trees that were inefficient in diameter growth. When young, survivors of the widest spacing did have the highest average $\mathrm{RGR}_{\mathrm{DBH}}$. However, after 55 years, all survivors had about the same diameter growth efficiency, regardless of the initial density. In the end, survivors that experienced more intense competition, possibly by making diameter growth a high priority in carbon allocation, achieved the same $\mathrm{RGR}_{\mathrm{DBH}}$ as did those that experienced less intense competition.
\end{abstract}

(C) 2007 Elsevier B.V. All rights reserved.

Keywords: Competition; Cryptomeria japonica; Growth efficiency; Relative growth rate

\section{Introduction}

Relative growth rate (RGR), defined as the rate of size increase per unit of time per unit of size (i.e., $\mathrm{RGR}=\left(d_{\text {size }} /\right.$ $\left.d_{\text {time }}\right)(1 /$ size), Hunt, 1990), plays a prominent role in plant ecology. As a measure of growth efficiency (Blackman, 1919), a higher RGR means that an individual plant, or a species, can grow more efficiently when resources are limited. Thus, the trait has been considered to be a sensitive measure of competitive ability (e.g., Ford, 1975, 1984; Harper, 1977; Grime, 1979; Hara, 1984; Goldberg and Landa, 1991; Larocque and Marshall, 1993), and several competition indices have been developed based on the trait (Weigelt and Jolliffe, 2003). Cannell et al. (1984) suggested that the only way to assess intraspecific competition is to observe the distribution of RGR.

\footnotetext{
* Corresponding author. Tel.: +8862 33664628; fax: +886223639247. E-mail address: btguan@ntu.edu.tw (B.T. Guan).
}

If RGR is indeed a good measure of competitive ability, then the trait should correlate positively with survivorship. Although several studies have examined the relation between RGR and survivorship (e.g., Sletvold, 2005), those studies were based mainly on short-term experiments with annual plants or seedlings of perennial plants as the subjects. For perennials, such as trees, competition is a long and continuing process. It would be desirable to know under what circumstances a higher RGR does ensure long-term survivorship (Question 1). Another gap in plant ecology literature concerns the long-term effect of initial density on survivors' RGR. Will survivors under intense competition (e.g., high density) be as efficient as those that experience less intense competition (Question 2)?

In this study, using a functional growth analysis approach (Hunt, 1982) in conjunction with nonlinear mixed-effects (NLME) modeling, our objective was to answer the two questions based on long-term (1955-2005) data from a Japanese cedar (Cryptomeria japonica D. Don) spacing trial. To answer Question 1, we formulated Hypothesis 1: survivors, 
on the average, are more efficient than those trees that did not survive. To test this hypothesis accurately requires the annual growth and survival status information of each tree, which is usually unavailable. The best that we can do, based on periodic inventory data, is to use a retrospective and sequential approach to determine whether trees that are still alive in the $i$ th inventory grew more efficiently between the first and the $(i-1)$ th inventories than those that died between the $(i-1)$ th and the $i$ th inventories. To answer Question 2, we formulated Hypothesis 2: since more resources are available, survivors that experience less intense competition are more efficient (Sletvold, 2005), on the average, than those that experience more intense competition (i.e., the mean RGR of survivors increases with increasing initial spacing).

We tested the two hypotheses based on the RGR of diameter at breast height $\left(\mathrm{RGR}_{\mathrm{DBH}}\right.$, with $\mathrm{DBH}$ measured over-bark at $1.3 \mathrm{~m}$ above the ground). We used relative diameter growth rate $\left(\mathrm{RGR}_{\mathrm{DBH}}\right)$ as a measure of overall growth efficiency. Previous studies have suggested that diameter growth is last in the carbon allocation priority ranking for trees (Waring, 1983; Waring and Pitman, 1985). Therefore, any growth in DBH implies that a tree has acquired enough resources to meet all other demands. $\mathrm{RGR}_{\mathrm{DBH}}$ should therefore be an effective indication of a tree's overall growth efficiency (Larocque and Marshall, 1993; Larocque, 1998). However, Nilsson and Albrektson (1993) suggested that under intense competition for light, diameter growth becomes a high priority. Despite different views, both arguments suggest that $\mathrm{RGR}_{\mathrm{DBH}}$ should be a robust measure of a tree's competitive ability.

\section{Materials and methods}

\subsection{Description of the spacing trial}

Japanese cedar, native to China and Japan, was introduced to Taiwan during the 1890s. It is one of the fastest growing plantation tree species in Taiwan. The spacing trial is located in the National Taiwan University Experimental Forest, Si-Tou Forest District of central Taiwan $\left(120^{\circ} 47^{\prime} \mathrm{E}, 23^{\circ} 40^{\prime} \mathrm{N}\right.$, elevation $1200 \mathrm{~m})$.

The spacing trial was established in 1950, using 1-year cuttings with square spacings of $1,2,3,4$, and $5 \mathrm{~m}$ (i.e., initial densities of $10,000,2500,1111,625$, and 400 trees/ha, respectively). The experimental design was a completely randomized design with three plots (replicates) for each spacing. The area of each plot was 0.1 ha $(25 \mathrm{~m} \times 40 \mathrm{~m})$, with a 5-m spacing between plots. The entire spacing trial was established within a 3 ha area. The first inventory was conducted in 1955, with subsequent inventories taken in $1960,1965,1980,1985,1995,2000$, and 2005. We will refer to the years since establishment as "stand age". While DBH was measured for all survived trees in every inventory, only a portion of the trees was measured for their heights in the first two inventories. The plots of 1-m spacing were thinned immediately after the 1965 inventory. Data from the thinned plots were excluded from this study.

\subsection{Data}

To minimize edge effects, only data from trees located approximately within the central $70 \%$ area of each plot were used (956 trees in total). As expected, trees grown under wider spacings were larger, on the average, at stand age 55 (Fig. 1), and the overall mortality rate increased with decreasing spacing (Table 1). Within each spacing, the mean growth trends were similar, except for one plot in the 3-m spacing (Fig. 1). For the 2-m and 3-m spacings, self-thinning began between stand ages 15 and 30. For the other two spacings, significant mortality did not occur until after stand age 35 (Fig. 2). However, self-thinning probably was not the only cause of mortality. Density-independent factors, such as typhoons, probably also contributed.

To test the first hypothesis, we began our analysis with the 1980 (fourth) inventory since we needed at least three points in time to fit a nonlinear growth model (described below). In addition, we focused only on spacings with at least five dead trees in a particular inventory. Thirteen data sets were so created-five for the 2-m spacing, four for the 3-m spacing, three for the 4-m spacing, and one for the 5-m spacing (Table 1). For the 3-m spacing at stand age 55, we used only data from one particular plot since all the dead trees were from that plot alone.

We used survivors in every inventory, starting from the 1965 (third) inventory, in order to test the second hypothesis (six data sets in all).

\subsection{DBH growth model}

Since the mean DBH growth trends over the 50-year period for all plots seemed to follow a simple asymptotic curve (Fig. 1), we adopted a two-parameter monomolecular model (Hunt, 1982; Zeide, 1993) of the form:

$$
\operatorname{DBH}(t)=\operatorname{Asymp} \cdot[1-\exp (-\mathrm{rc} \cdot t)]
$$

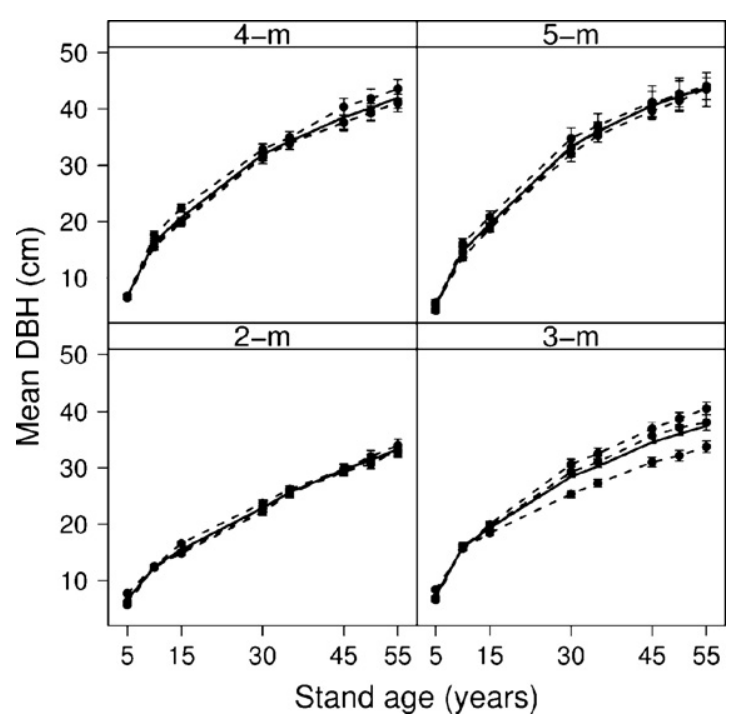

Fig. 1. Mean DBH growth trends for each spacing based on the survivors of each inventory. Dashed lines represent the plot-level trends, solid lines represent the spacing-level trends, and the error bars represent the plot-level mean$\mathrm{s} \pm 1 \mathrm{~S} . \mathrm{E}$. 
Table 1

Summary of mortality information for the data used in testing Hypothesis 1

\begin{tabular}{|c|c|c|c|c|c|c|c|c|c|c|c|}
\hline \multirow[t]{2}{*}{ Spacing } & \multicolumn{8}{|c|}{ Inventory year (stand age) } & \multirow{2}{*}{$\begin{array}{l}\text { Total dead } \\
\text { trees }\end{array}$} & \multirow{2}{*}{$\begin{array}{l}\text { Total } \\
\text { trees }^{\text {a }}\end{array}$} & \multirow[t]{2}{*}{ Mortality $^{\mathrm{b}}$} \\
\hline & $1955(5)$ & $1960(10)$ & 1965 (15) & $1980(30)$ & $1985(35)$ & $1995(45)$ & $2000(50)$ & $2005(55)$ & & & \\
\hline $2-m$ & $0^{\mathrm{c}}$ & 17 & 6 & $116^{\mathrm{d}}$ & 42 & 76 & 9 & 29 & 295 & 470 & 0.63 \\
\hline 3-m & 0 & 5 & 0 & 27 & 10 & 34 & 2 & 8 & 86 & 242 & 0.36 \\
\hline 4-m & 0 & 0 & 0 & 12 & 3 & 16 & 1 & 5 & 37 & 156 & 0.24 \\
\hline $5-m$ & 0 & 3 & 1 & 4 & 3 & 11 & 1 & 0 & 23 & 88 & 0.26 \\
\hline Total dead trees & 0 & 25 & 7 & 159 & 58 & 137 & 13 & 42 & 441 & & \\
\hline
\end{tabular}

${ }^{a}$ Number of trees tallied in the first inventory.

b Overall mortality rate.

c Table entries are the number of dead trees in each inventory.

d Numbers in boldface indicate the data sets used to test Hypothesis 1.

to model DBH growth trends. In the model, $\mathrm{DBH}(t)$ is $\mathrm{DBH}$ $(\mathrm{cm})$ at stand age $t$ (years), Asymp is the asymptote $(\mathrm{cm})$ of the model, and rc is the growth-rate coefficient $\left(\right.$ year $\left.^{-1}\right)$. This model implies that the rate of DBH growth is proportional to the difference between the ultimate DBH when the time approaches infinity (i.e., Asymp) and the current DBH (Erickson, 1976; Hunt, 1982). From Eq. (1), we can derive:

$\operatorname{RGR}_{\mathrm{DBH}}(t)\left(\mathrm{cm} \mathrm{cm}^{-1} \mathrm{year}^{-1}\right)=\frac{\mathrm{rc} \cdot \exp (-\mathrm{rc} \cdot t)}{1-\exp (-\mathrm{rc} \cdot t)}$

as the instantaneous relative DBH growth rate at stand age $t$ (Hunt, 1982; Zeide, 1993). It is clear from Eq. (2) that RGR DBH is independent of tree size and a monotonically decreasing function of rc. Because of the monotonicity, we used $\mathrm{rc}$ as a surrogate measure for $\mathrm{RGR}_{\mathrm{DBH}}$ in this study.

\subsection{Statistical analysis}

Because the data were longitudinal, we used either a generalized nonlinear least-squares or a NLME modeling approach to analyze the data, depending on whether it was

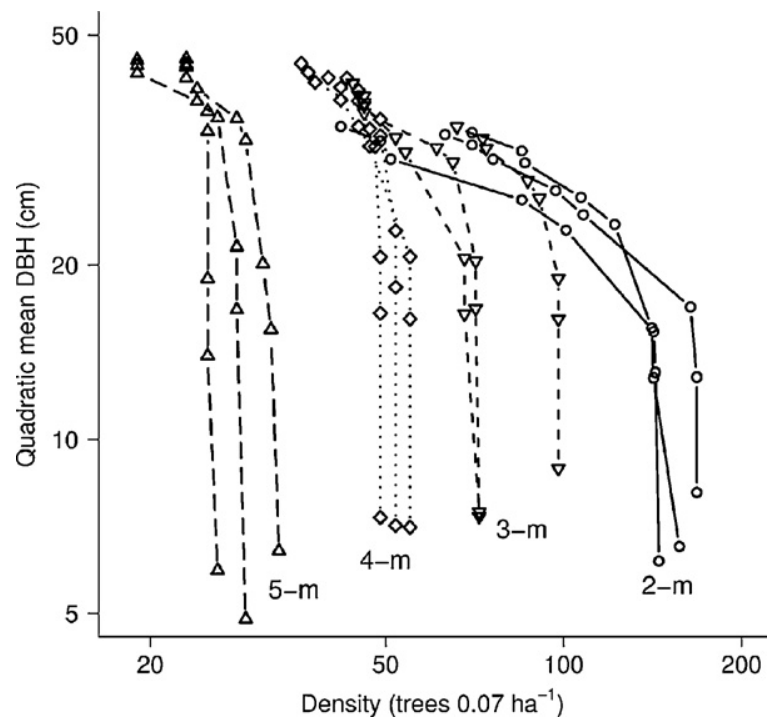

Fig. 2. The relation between the residual densities (log scale) and the quadratic mean DBH (log scale) for the data used in this study. necessary to treat any of the two parameters in the above monomolecular model as a mixed-effect. In mixed-effects modeling, a fixed effect represents the population average, whereas the associated random effect represents random deviations of individual trees from the fixed effect (Pinheiro and Bates, 2000). In all cases, a two-level modeling approach was used, with plots as the first level and individual trees within each plot as the second level (i.e., trees nested within a plot). Random variations at the plot level might be due to environmental heterogeneities, whereas random variations at the tree level might be due to within-plot heterogeneities or genetic differences (Dijkstra and Lambers, 1989).

Under NLME, let $\mathrm{DBH}_{i j k}$ be the observed DBH of the $j$ th tree in the $i$ th plot at the $k$ th inventory, we modeled the DBH growth curve of an individual tree as

$$
\begin{aligned}
\mathrm{DBH}_{i j k}= & \left(\text { Asymp }_{\text {fixed }}+\text { Asymp }_{i}+\text { Asymp }_{i, j}\right) \\
& \times\left\{1-\exp \left[-\left(\mathrm{rc}_{\text {fixed }}+\mathrm{rc}_{i}+\mathrm{rc}_{i, j}\right) \cdot t_{k}\right]\right\}+\varepsilon_{i j k},
\end{aligned}
$$

where Asymp fixed, Asymp, Asymp $_{i, j}, \mathrm{rc}_{\mathrm{fixed}}, \mathrm{rc}_{i}$, and $\mathrm{rc}_{i, j}$ are the fixed-effect, the plot-, and tree-level random effects for the parameters Asymp and rc, respectively, $t_{k}$ is the stand age at the $k$ th inventory, and $\varepsilon_{i j k}$ is the within-group random error. In all of the models, stand age was the continuous covariate, and depending on the hypothesis, either the survival status (Hypothesis 1) or initial spacing (Hypothesis 2) was the discrete fixedeffect covariate.

For all models, we assumed that within-group errors distribute as $N\left(0, \sigma^{2} I\right)$. For NLME models, we also assumed that: (1) all the random effects were normally distributed; (2) the random effects for different plots were independent; (3) for different trees within the same plot, their random effects were also independent; (4) the random effects and the within-group errors were independent of each other.

All statistical analyses were conducted using $\mathrm{R}$ software ( $\mathrm{R}$ Development Core Team, 2006). We used the NLME package of $\mathrm{R}$ (Pinheiro et al., 2006) to fit generalized nonlinear least-squares and NLME models. To satisfy the independence and equal variance assumptions for the within-group errors, we used various options available in the NLME package (Pinheiro et al., 2006) until the residuals met the two assumptions. We used a likelihood ratio testing approach to determine the best random effect variance-covariance structure and to select the best 
Table 2

Summary of the random effect structures for models used to test the two hypotheses

\begin{tabular}{|c|c|c|c|}
\hline \multicolumn{2}{|c|}{ Hypothesis 1} & \multicolumn{2}{|c|}{ Hypothesis 2} \\
\hline Data set & Random effect structure & Data set & Random effect structure \\
\hline 2-m 1980 & plot $^{\mathrm{a}}=\mathrm{rc} \sim 1$, tree $^{\mathrm{a}}=\mathrm{rc} \sim 1$ & 1965 & plot $=$ Asymp $\sim 1$ \\
\hline 2-m 1985 & plot $=\mathrm{rc} \sim 1$, tree $=$ Asymp $\sim 1$ & 1980 & plot $=$ Asymp $+\mathrm{rc} \sim 1$, tree $=$ Asymp $\sim 1$ \\
\hline 2-m 1995 & plot $=\mathrm{rc} \sim 1$, tree $=$ Asymp $\sim 1$ & 1985 & plot $=$ Asymp $+\mathrm{rc} \sim 1$, tree $=$ Asymp $\sim 1$ \\
\hline $2-\mathrm{m} 2000$ & plot $=\mathrm{rc} \sim 1$, tree $=$ Asymp $\sim 1$ & 1995 & plot $=$ Asymp $+\mathrm{rc} \sim 1$, tree $=$ Asymp $\sim 1$ \\
\hline 2-m 2005 & plot $=\mathrm{rc} \sim 1$, tree $=$ Asymp $\sim 1$ & & \\
\hline 3-m 1985 & plot $=\operatorname{pdDiag}($ Asymp $+\mathrm{rc} \sim 1)$, tree $=$ Asymp $\sim 1$ & & \\
\hline 3-m 1980 & No random-effect, model fitted by generalized nonlinear least-squares & & \\
\hline 3-m 1995 & plot $=\operatorname{pdDiag}($ Asymp $+\mathrm{rc} \sim 1)$, tree $=$ Asymp $\sim 1$ & & \\
\hline 3-m 2005 & tree $=$ Asymp $\sim 1$ & & \\
\hline 4-m 1980 & plot $=$ Asymp $\sim 1$ & & \\
\hline 4-m 1995 & tree $=$ Asymp $\sim 1$ & & \\
\hline 4-m 2005 & tree $=$ Asymp $\sim 1$ & & \\
\hline 5-m 1995 & tree $=$ Asymp $\sim 1$ & & \\
\hline
\end{tabular}

${ }^{\text {a }}$ Plot or tree level random effect; pdDiag denotes that the corresponding random effect variance-covariance matrix is a diagonal one. Notations follow Pinheiro and Bates (2000).

options to account for the within-group variance heterogeneity and serial correlation (Pinheiro and Bates, 2000).

We used graphical methods (e.g., residuals diagnostic plots, the observed trend augmented by the fitted trend plots) and the squared Pearson's correlation coefficient $\left(r^{2}\right)$ between the observed and the fitted means to assess the adequacy and performance of a final fitted model.

\section{Results}

\subsection{Summary of the fitted models}

For all data sets, at least one of the two parameters was treated as a mixed-effect, except in one case (Table 2). In almost all of the NLME fitted models, the random component of the parameter rc was present at the plot level, rather than at the tree level.

For NLME fitted models, all of the random effects met the normality assumption. For all of the fitted models, the residuals met the normality assumption, except in four cases. For those cases, departures from normality were mainly due to the presences of influential observations ("outliers"), which were likely caused by measurement or recording errors (e.g., sudden increases in DBH growth, trees were larger in the previous inventory). In those data sets, the distributions of the standardized residuals were symmetric, but heavy tailed. We chose to not delete the outliers or to transform those data, since such residual patterns tend to inflate the estimated within-group error variances. In turn, this leads to more conservative tests (Pinheiro and Bates, 2000).

In most of the cases, the within-group unequal variance was overcome by using a combination of an exponential variance function (varExp in NLME package) with stand age as the variance covariate, and a scaling of the within-group variance estimate for each plot or spacing (varIdent variance function in NLME package). For the majority of the fitted models, we accounted for their serial correlation structure by using either an $\operatorname{AR}(1), \operatorname{AR}(2), \operatorname{ARMA}(1,1)$, or $\operatorname{ARMA}(2,1)$ process.

\subsection{Results for testing Hypothesis 1}

The predicted mean growth trends from the 13 fitted models matched the corresponding observed trends closely (Figs. 3-6).

For the 2-m spacing, the estimated population mean growthrate coefficients (i.e., the fixed-effect component of the parameter $\left.\mathrm{rc}, \mathrm{rc}_{\mathrm{fixed}}\right)$ for the survivors were significantly smaller than those for the dead trees, except at stand age 30 (Fig. 7). For the 3-m spacing, we detected a significant difference in $\mathrm{rc}_{\mathrm{fixed}}$ between the dead and the survived groups only at stand age 55. Compared to the dead trees, survivors at stand age 55 did have a more efficient diameter growth between stand ages 5 and 50. For the 4-m spacing, trees that were dead at either age 45 or 55 had $\mathrm{rc}_{\text {fixed }}$ values that were significantly higher from stand age 5 up to stand age 35 or 50 , respectively, than those of the survivors. For the widest spacing, results from the only data set showed that trees that died between stand ages 35 and 45 had a significantly lower $\mathrm{rc}_{\text {fixed }}$ between stand ages 5 and 35 than that of the survivors.

As expected, the group with a significantly lower $\mathrm{rc}_{\text {fixed }}$ leading to the $i$ th inventory also had a greater mean DBH in the $(i-1)$ th inventory (Figs. 3-6). The dead groups all had higher $\mathrm{rc}_{\text {fixed }}$ values (except in two cases) and larger standard errors (Fig. 7). The larger standard errors might be due to both the limited numbers of dead trees in the data sets and densityindependent factors.

\subsection{Results for testing Hypothesis 2}

The predicted trends from the six fitted models all matched the corresponding observed trends quite satisfactorily (Fig. 8). As expected, the mean DBHs for the wider spacings were greater than those for the narrower spacings throughout the inventories (Fig. 8).

Between stand ages 5 and $10, \mathrm{rc}_{\text {fixed }}$ values for the survivors were about the same, regardless of the initial spacings (Fig. 9). During that period, the survivors of the 2-m spacing actually 

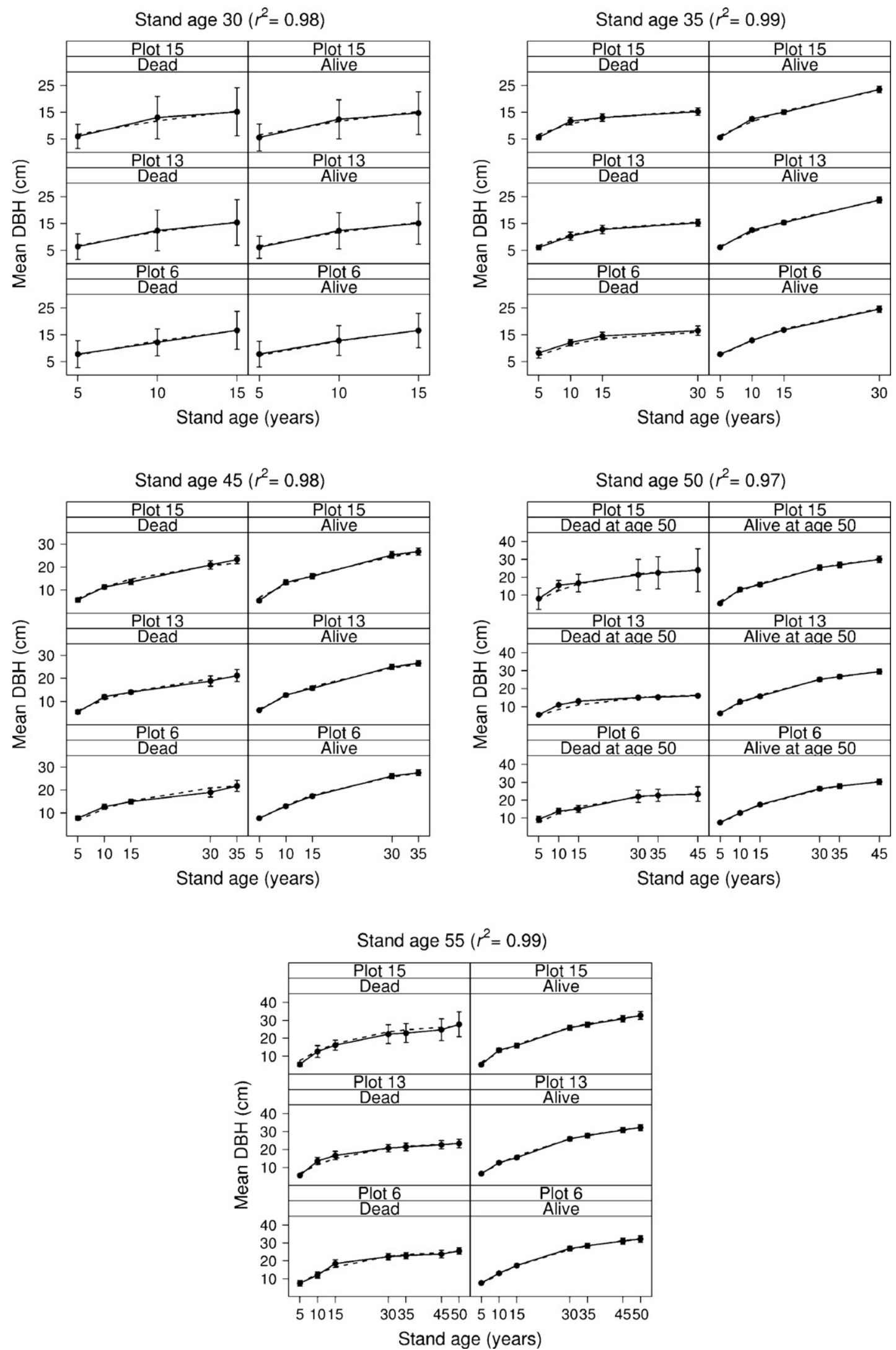

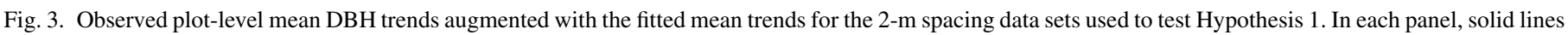

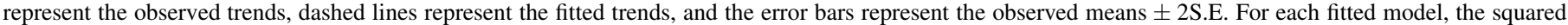
Pearson's correlation coefficient $\left(r^{2}\right)$ between the observed and the fitted plot-level means is also provided. 

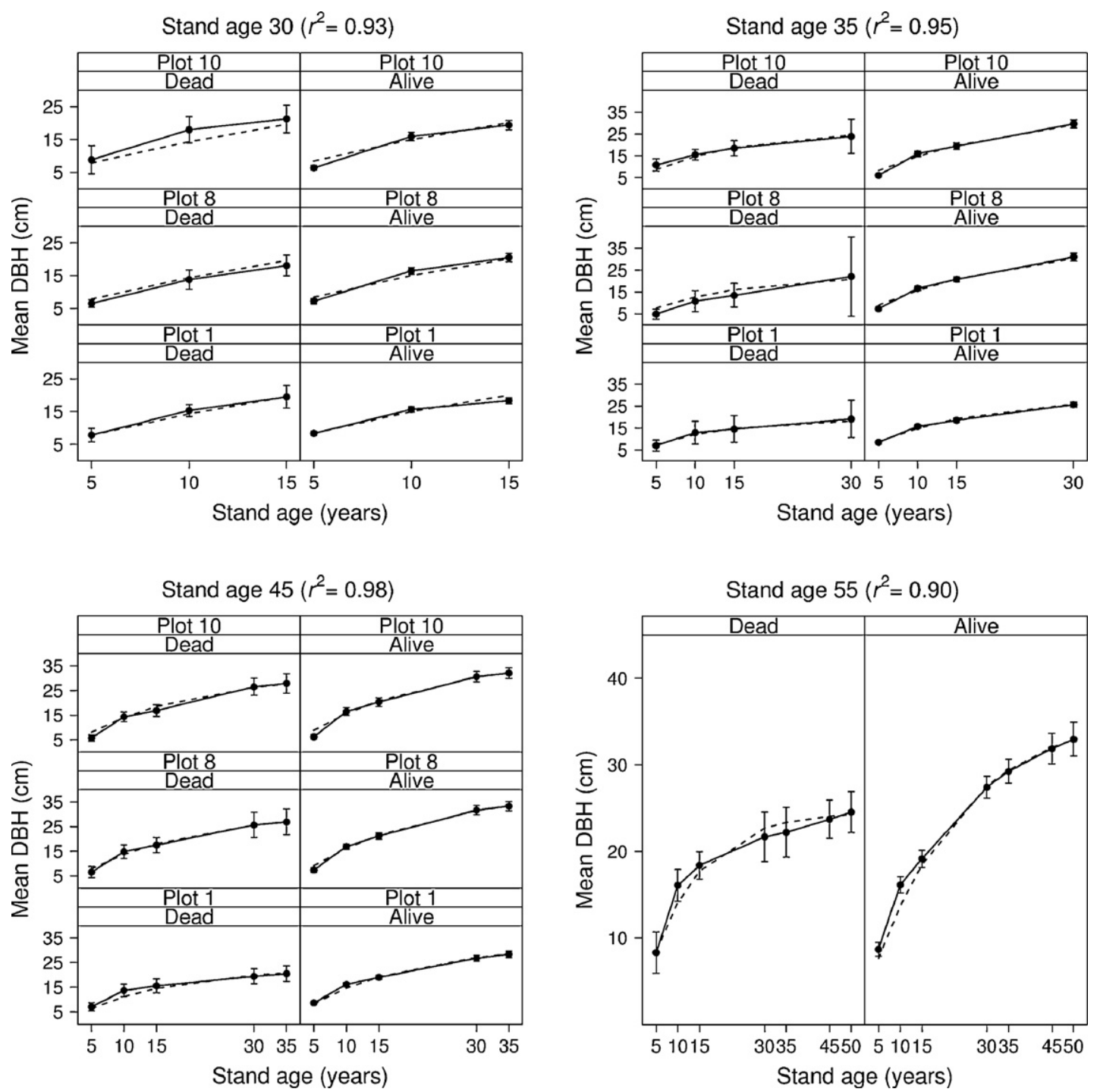

Fig. 4. Observed plot-level mean DBH trends augmented with the fitted mean trends for the 3-m spacing data sets used to test Hypothesis 1 . Refer to Fig. 3 for the legends.

had the lowest $\mathrm{rc}_{\text {fixed }}$ value and the smallest standard error. At stand age 30, the survivors in the two wider spacings had smaller $\mathrm{rc}_{\mathrm{fixed}}$ values. However, as the trees aged, only the survivors in the 5 -m spacing had a significantly smaller $\mathrm{rc}_{\mathrm{fixed}}$ than that of the survivors in the other spacings until stand age 50 , at which time $\mathrm{rc}_{\text {fixed }}$ values for all of the survivors were about the same, except for those in the 3-m spacing.

For all spacings, the standard errors for the $\mathrm{rc}_{\text {fixed }}$ values declined through time, which suggests that the mean diameter growth efficiency for the survivors in each spacing became less variable as trees aged (Fig. 9).

\section{Discussion}

\subsection{Hypothesis 1: survivors are more efficient}

Are survived Japanese cedars more efficient? Based on the only data set from the widest spacing, that certainly was not the case. Instead, the opposite was true. For the other spacings, the survivors were no more efficient in diameter growth prior to the onset of self-thinning. Once self-thinning began, the survivors were more efficient indeed (Figs. 2 and 7).

Thus, our results partially supported this hypothesis. When density is low or competition is weak, a higher $\mathrm{RGR}_{\mathrm{DBH}}$ does not guarantee survival. Under such circumstances, densityindependent factors are likely to be the main cause of mortality. Since Taiwan is in a typhoon-prone area, we suspected that disturbance might be an important cause of mortality. When density was the main cause of mortality, however, Japanese cedars with a lower $\mathrm{rc}_{\text {fixed }}$ value (i.e., a higher $\mathrm{RGR}_{\mathrm{DBH}}$ ) did have a higher likelihood to survive (Fig. 7). Our findings suggest that self-thinning eliminates Japanese cedars that were less efficient in diameter growth. The findings confirm the assertion made by Ford (1984) and Perry (1985), and provide an answer as to the cause of mortality in self-thinning (Thomas and Weiner, 1989). Previous studies suggested that competition reduces the RGR of small trees relative to that of larger trees (Ford, 1975, 1984; Cannell et al., 1984; Perry, 1985; Larocque 

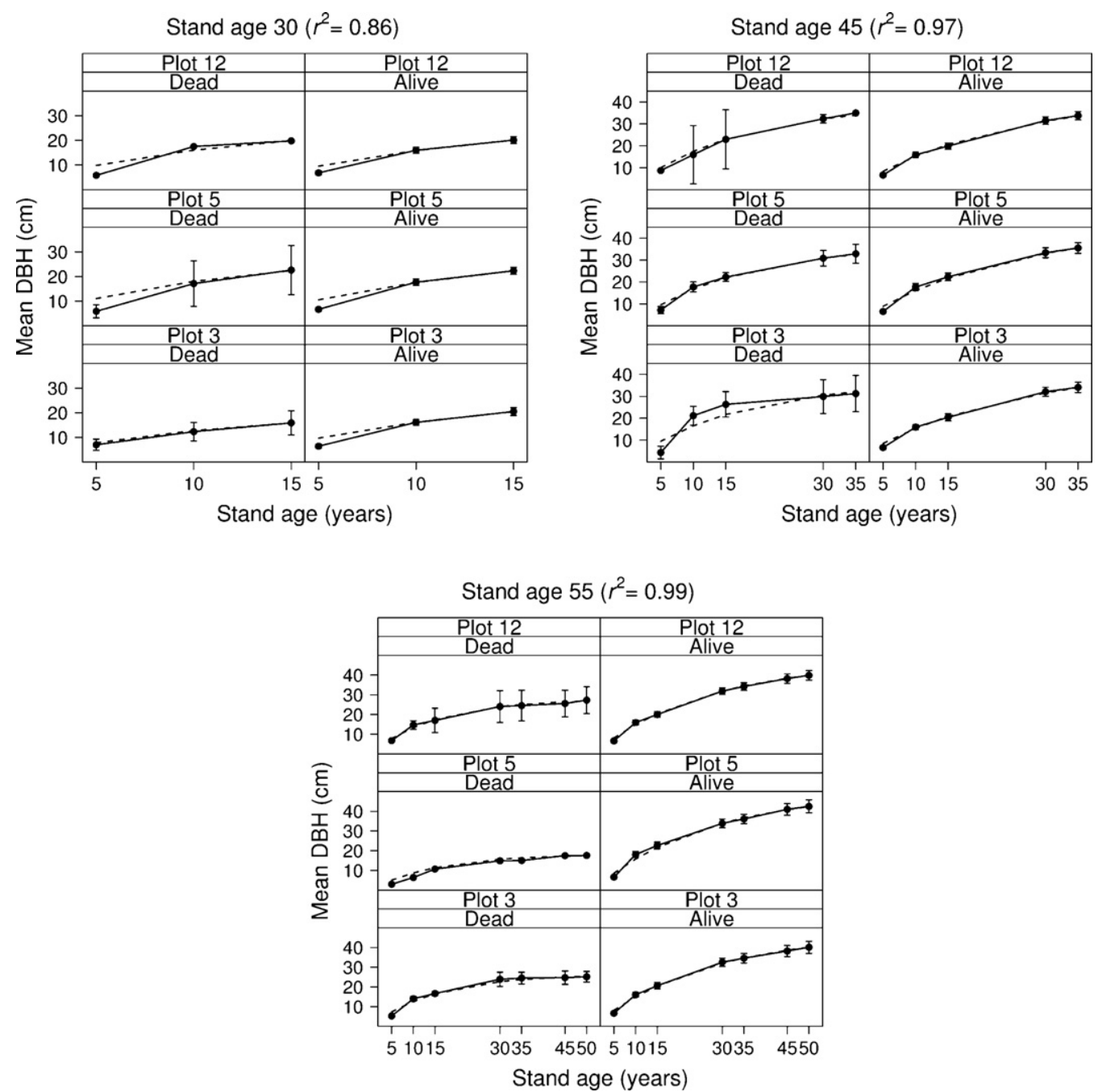

Fig. 5. Observed plot-level mean DBH trends augmented with the fitted mean trends for the 4-m spacing data sets used to test Hypothesis 1 . Refer to Fig. 3 for the legends.

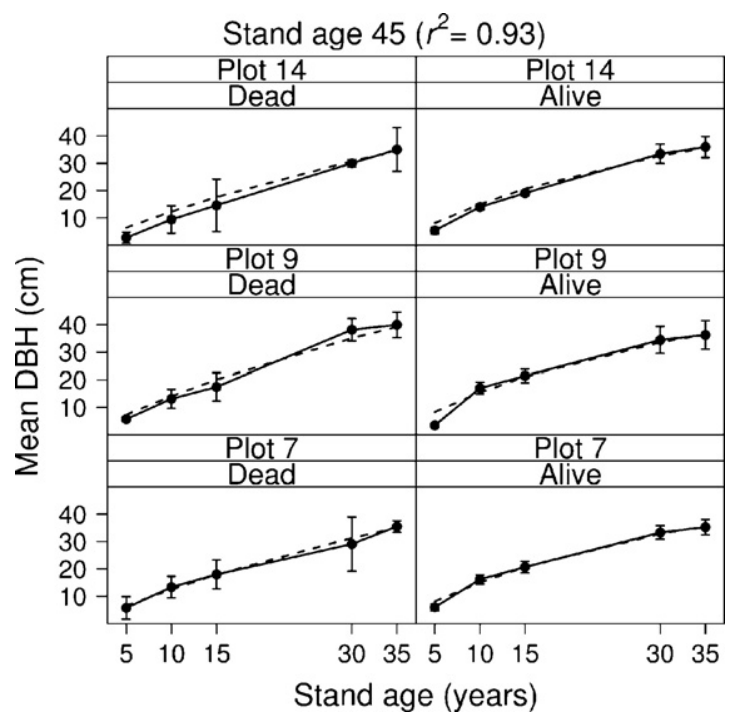

Fig. 6. Observed plot-level mean DBH trends augmented with the fitted mean trends for the 5-m spacing data sets used to test Hypothesis 1. Refer to Fig. 3 for the legends. and Marshall, 1993; Larocque, 1998). Results from the 2-m spacing confirm that assertion, since all dead Japanese cedars after the onset of self-thinning were small trees that had a lower $\mathrm{RGR}_{\mathrm{DBH}}$.

In our data, 15 years separated the third and fourth inventories. That was also the period during which heavy selfthinning took place in the higher density plots (about $25 \%$ of the trees in the 2-m spacing died during that time). Unfortunately, without data from that period, we could only conclude that, for trees in the higher density plots died during that period, they were as efficient as the survivors were during the first 15 years (Fig. 7).

Results from the 3-m spacing were the exceptions to the general trend presented above. Density-independent factors might be the cause. For that spacing, the plot-level mean DBHs for trees that died between stand ages 30 and 35 or between 35 and 45 all had large standard errors at stand age 30 or 35 , respectively (Fig. 4). This indicated that even relatively large Japanese cedars died during the corresponding periods. Since large trees had higher growth efficiencies in general, their 


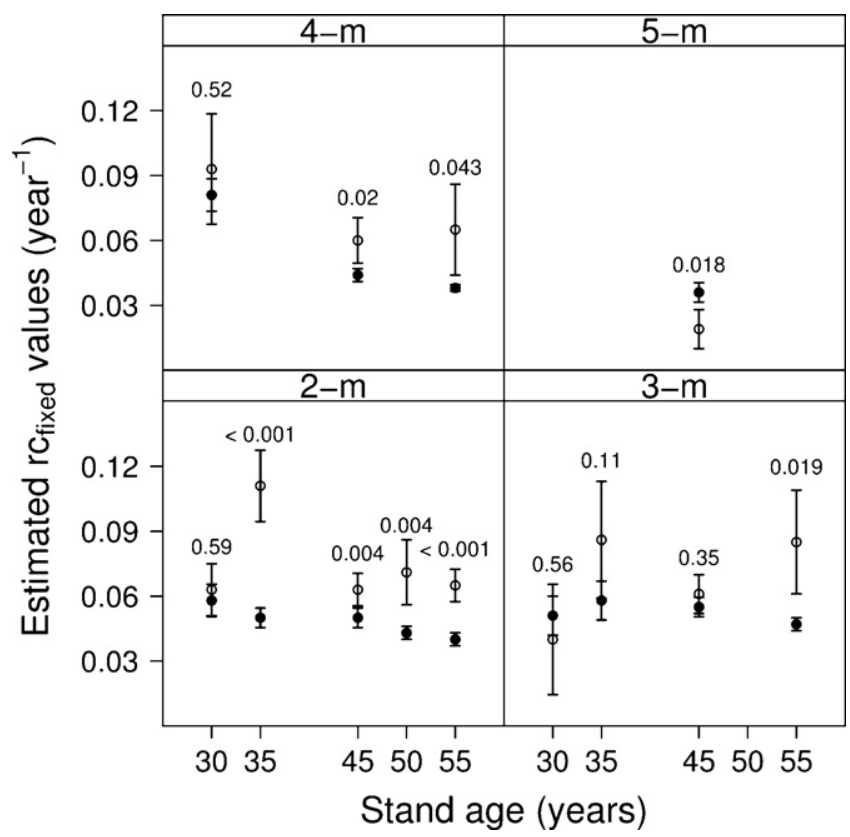

Fig. 7. Estimated population mean growth-rate coefficients, $\mathrm{rc}_{\mathrm{fixed}}$, of the survived (O) and dead $(\bigcirc)$ trees for each spacing in each inventory, with the error bars representing means \pm 2 S.E. The number above a set of error bars is the $P$-value that the estimated $\mathrm{rc}_{\text {fixed }}$ values of the two groups are equal.

deaths would increase the estimated standard errors in $\mathrm{rc}_{\text {fixed }}$. On the other hand, density-dependent mortality was probably more important since the $\mathrm{rc}_{\text {fixed }}$ values were still higher for the dead trees (Fig. 7).

It is often difficult to weigh the relative importance of density-dependent and density-independent mortalities. If we can assume that the main victims of self-thinning are trees with low growth efficiencies, as this study and others have demonstrated, then by comparing the estimated $\mathrm{rc}_{\text {fixed }}$ values and the associated standard errors between the dead trees and the survivors, we might be able to determine the relative importance of the two types of mortality. When density-dependent mortality is the main, or only, cause of tree deaths, we expect not only a larger $\mathrm{rc}_{\text {fixed }}$ for the dead trees, but also a smaller estimated standard error (e.g., 2-m spacing in Fig. 7). In contrast, if random mortality is the main cause of deaths, we expect both the $\mathrm{rc}_{\text {fixed }}$ values and the standard errors between the survived and the dead trees to be similar (e.g., 5-m spacing in Fig. 7). Based on this reasoning, we concluded that density-dependent mortality was the main cause of deaths over the 50-year period for the spacing trial.

In general, Japanese cedars recorded as dead in a particular inventory had much slower growth trends leading to that inventory (especially the 2-m spacing, Fig. 3). Correspondingly, there was a decreasing trend for both $\mathrm{rc}_{\text {fixed }}$ values and standard errors for the survivors in each spacing (Fig. 7). This result suggested that Japanese cedars died because they were unable to grow efficiently over an extended period. Otherwise, the average growth trends of the dead and survived trees should match closely, except at the end. This finding supports the competition-induced mortality modeling approach currently used in several gap models (e.g., Botkin, 1993), in which a tree dies when it fails to meet the minimum required annual diameter increment for several consecutive years.

\subsection{Hypothesis 2: survivors' $R G R_{D B H}$ increases with increasing initial spacing}

What is the long-term effect of initial spacing on survivors' $\mathrm{RGR}_{\mathrm{DBH}}$ ? During the first 15 years after stand establishment, when competition was likely to be weak, initial density had no effect on survivors' diameter growth efficiency. It is evident that as time progressed, Japanese cedars that were grown in a less stressful environment had higher efficiencies since more resources were available to them (Fig. 9). However, with the onset of self-thinning, survivors that experienced more intense competition also became efficient in diameter growth. As the stands matured, all survived Japanese cedars had about the same $\mathrm{RGR}_{\mathrm{DBH}}$, regardless of the initial spacing. Thus, our results partially supported the second hypothesis. However, it would be incorrect to simply conclude that initial density had little, or no, long-term effect on survivors' $\mathrm{RGR}_{\mathrm{DBH}}$.

The rc $_{\text {fixed }}$ values of survivors that experienced more intense competition declined (i.e., $\mathrm{RGR}_{\mathrm{DBH}}$ increased) through time (Fig. 9), likely the result of re-prioritizing carbon allocation to height and diameter growth (Nilsson and Albrektson, 1993). Trees grown under high density must first allocate carbon to height growth in order to survive. In order to grow tall, trees must also allocate carbon to radial growth. The declining trends for both $\mathrm{rc}_{\text {fixed }}$ and the associated standard errors supported the above statement (Fig. 9). In that respect, intense intraspecific competition likely thins out Japanese cedars that were unable to make such an adjustment. In contrast, the average $\mathrm{RGR}_{\mathrm{DBH}}$ for survivors in the widest spacing peaked around age 30, and then declined (Fig. 9), probably because of the accumulation of non-productive tissues (Perry, 1985). Thus, two trends in survivors' $\mathrm{RGR}_{\mathrm{DBH}}$ emerged from our study. Japanese cedars experienced more intense competition gaining diameter growth efficiency through time, whereas those that experienced less intense competition lost diameter growth efficiency through time. These two trends led to the observed results.

\subsection{Other considerations}

For trees, the best measure of growth efficiency probably is the production efficiency, that is, total biomass increase per unit of leaf area (Reid et al., 2004; Adegbidi et al., 2005). However, production efficiency is difficult to measure accurately in practice. Relative height growth rate is also a sensitive measure of competitive ability, as height is critical to tree survival (Cannell et al., 1984). However, for large trees their heights are also difficult to measure accurately. In this study, we adopted $\mathrm{RGR}_{\mathrm{DBH}}$ as a measure of the overall growth efficiency, based on the assumptions that radial growth is the lowest in carbon allocation priority ranking (Waring, 1983; Waring and Pitman, 1985), and that trees 

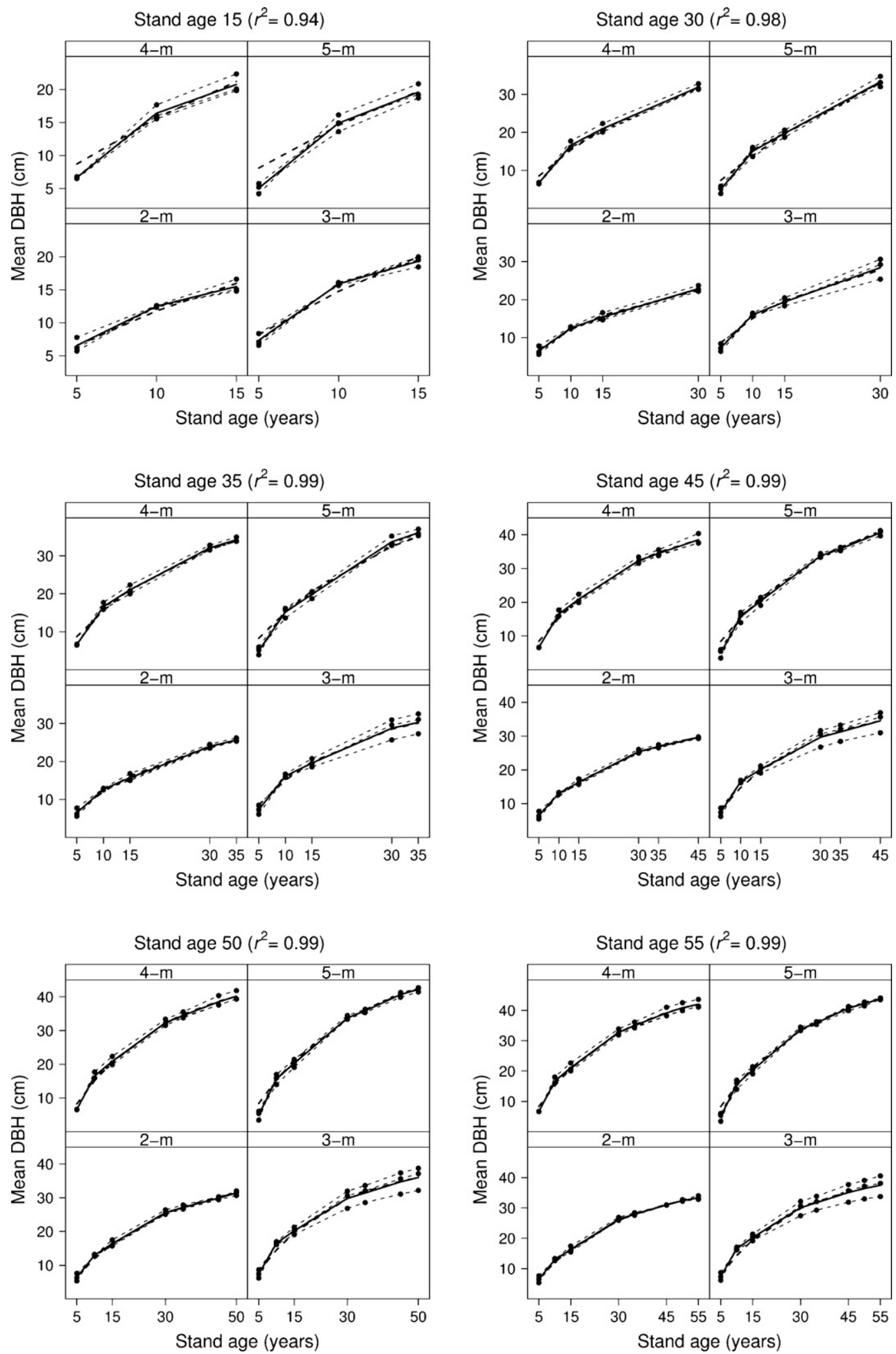

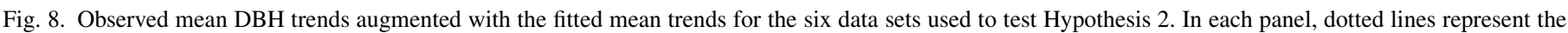

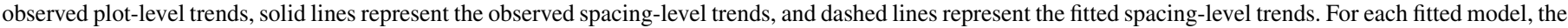
squared Pearson's correlation coefficient $\left(r^{2}\right)$ between the observed and the fitted spacing-level means is also provided.

experiencing intense competition might make radial growth a high priority (Nilsson and Albrektson, 1993). Both views suggest that $\mathrm{RGR}_{\mathrm{DBH}}$ should be a sensitive measure of competitive ability, and our results supported the contention, as the $\mathrm{RGR}_{\mathrm{DBH}}$ of the survivors in a crowded environment increased as competition intensified.

Among the individuals within a population, variations in RGR could be due to random variations (e.g., due to genetic 


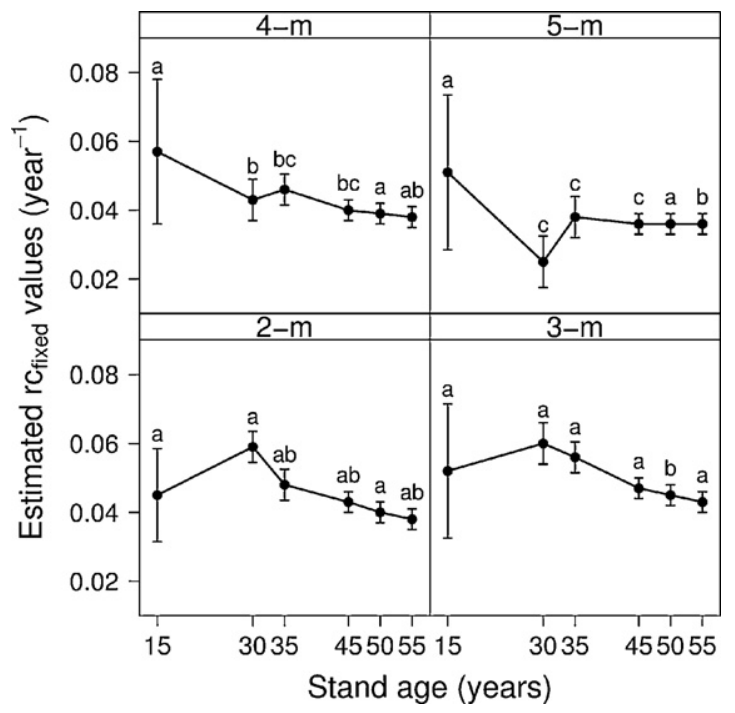

Fig. 9. Estimated population mean growth-rate coefficients, $\mathrm{rc}_{\text {fixed }}$, trends of each spacing based on the survivors in each inventory, with the error bars representing means \pm 2 S.E. At a given stand age, estimated $\mathrm{rc}_{\text {fixed }}$ values marked by different letters differ significantly $(P<0.05)$.

differences, Dijkstra and Lambers, 1989), competition, or both. Using a mixed-effect modeling approach, we were able to test explicitly whether the parameter rc, hence $\mathrm{RGR}_{\mathrm{DBH}}$, should be considered as a random effect at the tree level, and found that, for the majority of the cases, it should not (Table 2). Since the trees planted in the spacing trial were cuttings from a population of Japanese cedar, the result is no surprise. At that level, the "variation" in rc can be explained by either survival status or initial spacing. Thus, our findings supported the assertion that one could assess intraspecific competition by examining the distribution of RGR within a stand (Ford, 1975; Cannell et al., 1984; Wyszomirski et al., 1999). The parameter did vary among the plots in some instances (Table 2), however. This suggests that, even in a small area, environmental heterogeneities could still exist and affect tree growth (Fajardo and McIntire, 2007; Fox et al., 2007a,b). Nevertheless, we suggest that future studies should differentiate among the causes of variations in RGR.

Several plant competition or growth models used the $\mathrm{RGR}_{\mathrm{DBH}}$ of isolated individuals as the basis on which to derive $\mathrm{RGR}_{\mathrm{DBH}}$ for individuals in a crowded environment (e.g., Merriam et al., 1995) or to detect the mode of competition (e.g., Hara, 1992), as suggested by Hypothesis 2 . However, our study has shown that the hypothesis might not hold, at least in the early and late stages of Japanese cedar stand development. Thus, we might want to consider other approaches in modeling the growth of individuals in a crowded environment.

\section{Acknowledgements}

Funding for this study was partially supported by National Science Council of Taiwan (NSC 94-2621-B-002-014). We deeply appreciate NTU Experimental Forest for permission to the use the data and for providing field supports. We also thank two reviewers for their comments.

\section{References}

Adegbidi, H.G., Jokela, E.J., Comerford, N.B., 2005. Factors influencing production efficiency of intensively managed loblolly pine plantations in a 1- to 4-year-old chronosequence. For. Ecol. Manage. 218, 245-258.

Blackman, V.H., 1919. The compound interest law and plant growth. Ann. Bot. 33, 353-360.

Botkin, D.B., 1993. Forest Dynamics: An Ecological Model. Oxford University Press, Oxford

Cannell, M.G.R., Rothery, P., Ford, E.D., 1984. Competition within stands of Picea sitchensis and Pinus contorta. Ann. Bot. 53, 349-362.

Dijkstra, P., Lambers, H., 1989. A physiological analysis of genetic variation in relative growth rate within Plantago major L. Funct. Ecol. 3, 577587.

Erickson, R.O., 1976. Modeling of plant growth. Annu. Rev. Plant Physiol. 27, 407-434.

Fajardo, A., McIntire, E.J.B., 2007. Distinguishing microsite and competition processes in tree growth dynamics: an a priori spatial modeling approach. Am. Nat. 169, 647-661.

Ford, E.D., 1975. Competition and stand structure in some even-aged plant monocultures. J. Ecol. 63, 311-333.

Ford, E.D., 1984. The dynamics of plantation growth. In: Bowen, G.D., Nambiar, E.K.S. (Eds.), Nutrition of Plantation Forests. Academic Press, London, pp. 17-52.

Fox, J.C., Bi, H., Ades, P.K., 2007a. Spatial dependence and individual-tree growth models. I. Characterising spatial dependence. For. Ecol. Manage. $245,10-19$.

Fox, J.C., Bi, H., Ades, P.K., 2007b. Spatial dependence and individual treegrowth models. II. Modelling spatial dependence. For. Ecol. Manage. 245, $20-30$.

Goldberg, D.E., Landa, K., 1991. Competitive effect and response: hierarchies and correlated traits in the early stages of competition. J. Ecol. 79, 10131030.

Grime, J.P., 1979. Plant Strategies and Vegetation Processes. Wiley, Chichester.

Hara, T., 1984. Modelling the time course of self-thinning in crowded plant populations. Ann. Bot. 53, 181-188.

Hara, T., 1992. Effects of the mode of competition on stationary size distribution in plant populations. Ann. Bot. 69, 509-513.

Harper, J.L., 1977. Population Biology of Plants. Academic Press, New York.

Hunt, R., 1982. Plant Growth Curves: The Functional Approach to Plant Growth Analysis. Edward Arnold, London.

Hunt, R., 1990. Basic Growth Analysis: Plant Growth Analysis for Beginners. Unwin Hyman, London.

Larocque, G.R., 1998. Functional growth analysis of red pine trees under variable intensities of competition. For. Chron. 74, 728-735.

Larocque, G.R., Marshall, P.L., 1993. Evaluating the impact of competition using relative growth rate in red pine (Pinus resinosa Ait.) stands. For. Ecol. Manage. 58, 65-83.

Merriam, R.A., Philips, V.D., Liu, W., 1995. Early diameter growth of trees in planted forest stands. For. Ecol. Manage. 75, 155-174.

Nilsson, U., Albrektson, A., 1993. Productivity of needles and allocation of growth in young Scots pine trees of different competitive status. For. Ecol. Manage. 62, 173-187.

Perry, D.A., 1985. The competition process in forest stands. In: Cannell, M.G.R., Jackson, J.E. (Eds.), Attributes of Trees as Crop Plants. Institute of Terrestrial Ecology, Huntingdon, pp. 481-506.

Pinheiro, J.C., Bates, D.M., 2000. Mixed-effects Models in S and S-Plus. Springer, New York.

Pinheiro, J.C., Bates, D.M., DebRoy, S., Sarkar, D., 2006. NLME: linear and nonlinear mixed effects models. $\mathrm{R}$ package version 3.1-79.

R Development Core Team, 2006. R: A language and Environment for Statistical Computing. R Foundation for Statistical Computing, Vienna.

Reid, D.E.B., Lieffers, V.J., Silins, U., 2004. Growth and crown efficiency of height repressed lodgepole pine; are suppressed trees more efficient? TreesStruct. Funct. 18, 390-398.

Sletvold, N., 2005. Density-dependent growth and survival in a natural population of the facultative biennial Digitalis purpurea. J. Ecol. 93, $727-736$. 
Thomas, S.C., Weiner, J., 1989. Growth, death and size distribution change in an Impatiens pallida population. J. Ecol. 77, 524-536.

Waring, R.H., 1983. Estimating forest growth and efficiency in relation to canopy leaf area. Adv. Ecol. Res. 13, 327-354.

Waring, R.H., Pitman, G.B., 1985. Modifying lodgepole pine stands to change susceptibility to mountain pine beetle attack. Ecology 66, 889-897.
Weigelt, A., Jolliffe, P., 2003. Indices of plant competition. J. Ecol. 91, 707720.

Wyszomirski, T., Wyszomirska, I., Jarzyna, I., 1999. Simple mechanisms of size distribution dynamics in crowded and uncrowded virtual monocultures. Ecol. Model. 115, 253-273.

Zeide, B., 1993. Analysis of growth equations. For. Sci. 39, 594-616. 